\title{
Importance and usage of chromosomal microarray analysis in diagnosing intellectual disability, global developmental delay, and autism; and discovering new loci for these disorders
}

\author{
Ahmet Cevdet Ceylan ${ }^{1,2^{*}}$ (D, Senol Citli ${ }^{1}$, Haktan Bagis Erdem ${ }^{3}$, Ibrahim Sahin ${ }^{3}$, Elif Acar Arslan $^{4}$ and Murat Erdogan ${ }^{5}$
}

\begin{abstract}
Background: Chromosomal microarray analysis is a first-stage test that is used for the diagnosis of intellectual disability and global developmental delay. Chromosomal microarray analysis can detect well-known microdeletion syndromes. It also contributes to the identification of genes that are responsible for the phenotypes in the new copy number variations.

Results: Chromosomal microarray analysis was conducted on 124 patients with intellectual disability and global developmental delay. Multiplex ligation-dependent probe amplification was used for the confirmation of chromosome 22q11.2 deletion/duplication. 26 pathogenic and likely pathogenic copy number variations were detected in 23 patients (18.55\%) in a group of 124 Turkish patients with intellectual disability and global developmental delay. Chromosomal microarray analysis revealed pathogenic de novo Copy number variations, such as a novel 2.9-Mb de novo deletion at $18 q 22$ region with intellectual disability and autism spectrum disorder, and a 22q11.2 region homozygote duplication with new clinical features.
\end{abstract}

Conclusion: Our data expand the spectrum of 22q11.2 region mutations, reveal new loci responsible from autism spectrum disorder and provide new insights into the genotype-phenotype correlations of intellectual disability and global developmental delay.

Keywords: Chromosomal microarray, Intellectual disability, Global developmental delay, Copy number variations, 22q11.2 homozygote duplication

\section{Background}

Advancements in molecular technology, such as chromosomal microarray analysis (CMA), has led to the discovery of new microdeletions and microduplications in patients with intellectual disability (ID), global developmental delay (GDD), epilepsy, and congenital anomalies (CA). ID and GDD are clinically heterogeneous neurodevelopmental

\footnotetext{
* Correspondence: acceylan@yahoo.com

*This study has been presented at the ASHG 2017 annual meeting.

${ }^{1}$ Trabzon Kanuni Training and Research Hospital, Medical Genetics Unit, Trabzon, Turkey

${ }^{2}$ Ankara Yıldırım Beyazıt University, Ankara Atatürk Training and Research Hospital, Department of Medical Genetics, Ankara, Turkey

Full list of author information is available at the end of the article
}

disorders seen in $1-3 \%$ of children [1]. CMA is a first-tier test in the evaluation of individuals with ID and GDD with the diagnostic yield ranging from 5 to $20 \%$ varying based on population examined $[2,3]$. The International Standard for the Consortium of Cytogenomic Array recommended CMA as a first-stage cytogenetic diagnostic test for patients with CA and ID / GDD.

CMA can detect well-known microdeletion syndromes. It also contributes to the identification of genes that are responsible for the phenotypes in the new copy number variations (CNVs). Chromosome 22q11.2 deletion syndrome and 22q11.2 duplication syndrome are good examples for microdeletion/microduplication syndromes.

(c) The Author(s). 2018 Open Access This article is distributed under the terms of the Creative Commons Attribution 4.0 International License (http://creativecommons.org/licenses/by/4.0/), which permits unrestricted use, distribution, and reproduction in any medium, provided you give appropriate credit to the original author(s) and the source, provide a link to the Creative Commons license, and indicate if changes were made. The Creative Commons Public Domain Dedication waiver (http://creativecommons.org/publicdomain/zero/1.0/) applies to the data made available in this article, unless otherwise stated. 
Chromosome 22q11.2 duplication syndrome was first explained in 1999, but research continues to explore new phenotypes of this syndrome [4]. When there are three copies of the 22q11.2 region, it is called 22q11.2 duplication, whereas four copies of this region are referred to as the tetrasomy of 22q11.2 region. When there are two copies of 22q11.1 region in both alleles, this is referred to as 22q11.2 homozygote duplication. If there are three copies in one allele and one copy in the other, it is called 22q11.2 triplication.

Autism is a childhood disorder that expresses itself through core problems in communication and social interaction skills, along with the presence of stereotypical behaviors. Autism spectrum disorder (ASD) does not have a fixed pattern since a number of different genes have been reported as responsible for this disorder [5]. CMA studies have a high potential in revealing novel gene-phenotype associations in relation to this disorder. In this study, new loci for autism have been discovered which will help us better understand the cause of the disease.

Herein, we present the diagnostic rates for CNVs, and the aberrations, with major clinical findings detected by CMA in a group of 124 Turkish patients with ID and GDD. We also present a case with 22q11.2 homozygote duplication and new phenotypic findings as a result. Our study will help better explain the genotype-phenotype associations of the 22q11.2 region.

\section{Methods}

\section{DNA extraction}

Genomic DNA of family members was extracted according to the manufacturer's standard procedure using the MagNA Pure Compact Nucleic Acid Isolation Kit I (Roche Diagnostic GmbH, Mannheim, Germany).

\section{Microarray analysis}

Affymetrix CytoScan Optima ${ }^{\circ}$ chips were used to perform CMA in 124 patients with ID and GDD at Trabzon Kanuni Training and Research Hospital. Data analysis was performed using Chromosome Analysis Suite 3.1 software. Data were presented as minimum coordinates (sequence positions of the first and last probes within the CNV) in the NCBI37/hg19 genome assembly. Variants were evaluated based on phenotype and using standard in silico tools [6]. The analysis and interpretation of the obtained results were performed by using public genomic databases, such as UCSC, OMIM, DGV, DECIPHER, CLINGEN.

\section{MLPA (multiplex ligation-dependent probe Amplication) analysis}

MLPA was performed as suggested by the manufacturer (MRC-Holland ${ }^{\circ}$, Amsterdam, The Netherlands). The
SALSA $^{\circ}$ MLPA $^{\circ}$ probemix P250 DiGeorge was used for the confirmation of chromosome 22q11.2 deletion/duplication. The standard deviation of all probes in the reference samples were $<0.10$ and the dosage quotient (DQ) of the reference probes in the patients' samples were between 0.80 and 1.20. DQ of the probes were between 0.40 and 0.65 for heterozygous deletion. DQ of the probes were between 1.30 and 1.65 for heterozygous duplication. DQ of the probes were between 1.75 and 2.15 for heterozygous triplication or homozygous duplication.

\section{Results}

Between May 2016 and April 2017, 124 patients were examined at the department of genetics for GDD/ID and CA. There were 73 males and 51 females. The age of the patients ranged from 15 days to 17 years. The Denver Developmental Test was used with patients up to 3 years of age, whereas the Standfort Benet Test was used for patients 4-6 years of age, and the WISC-R test for patients older than 6 . This study was conducted with patients who were not diagnosed with any syndromes previously and CMA was performed as the first-tier test on the subjects. Table 1 shows the clinical features of these cases and the CMA results.

In 23 individuals (from 23 families), CMA analysis revealed CNVs including 6 microduplications (2p25p24, 22q11.2 [2 cases], 2p25, 14q32, and 15q11.2), 14 microdeletions (1p36.3, 1q21 [2 cases], 2q36, 6p25.1p23, 6q25q27, 14q32, 15q11.2, 16q24, 18p11.3, 18q22, 18q21q23, 19p23, and 22q11.2) and 1 homozygote duplication identified in same locus (22q11.2) in a patient (Fig. 1).

Twenty one of the $26 \mathrm{CNVs}$ were interpreted as pathogenic, whereas 5 of the $26 \mathrm{CNVs}$ were interpreted as having uncertain clinical significance (UCS); likely pathogenic in accordance with the clinical findings about the patients and literature [7]. 7 of 26 $\mathrm{CNVs}$ were associated with well-known microdeletion/ microduplication syndromes. Interestingly, multiple CNVs have been identified in two of the patients including 2 different deletions (6q13q14 and 8q21.3) in one and 1 deletion (6q25) and 2 duplications (6q24.1 and 6q26) in another (Table 1).

The length of 17 of the CNVs were below $5 \mathrm{Mb}$ and they could not be detected with conventional karyotyping. The length of 7 of the CNVs were between 5 and $10-\mathrm{Mb}$. It is worth to note that siblings, whose parents were in consanguineous marriages and carried $22 \mathrm{q} 11.2$ duplication, were also diagnosed with $22 \mathrm{q} 11.2$ homozygote duplication. 23 of $26 \mathrm{CNVs}$ were de novo. Eight out of 23 families had consanguineous marriages. Only two of the case studies are presented below in detail, however, the summary of all clinical features and mutations observed in patients can be found in Table 1 . 
- Ceylon et al. Molecular Cytogenetics (2018) 11:54

Page 3 of 9

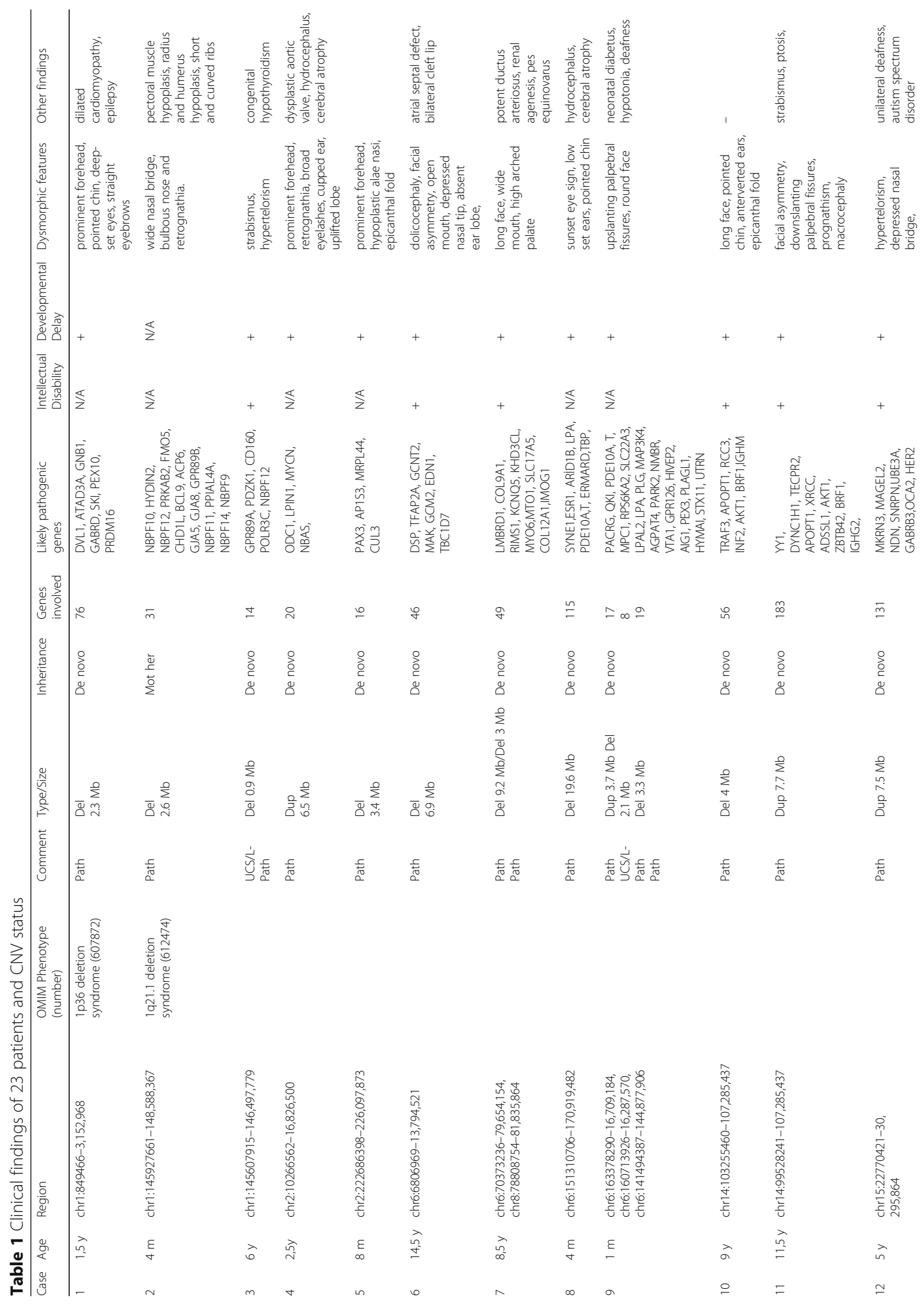




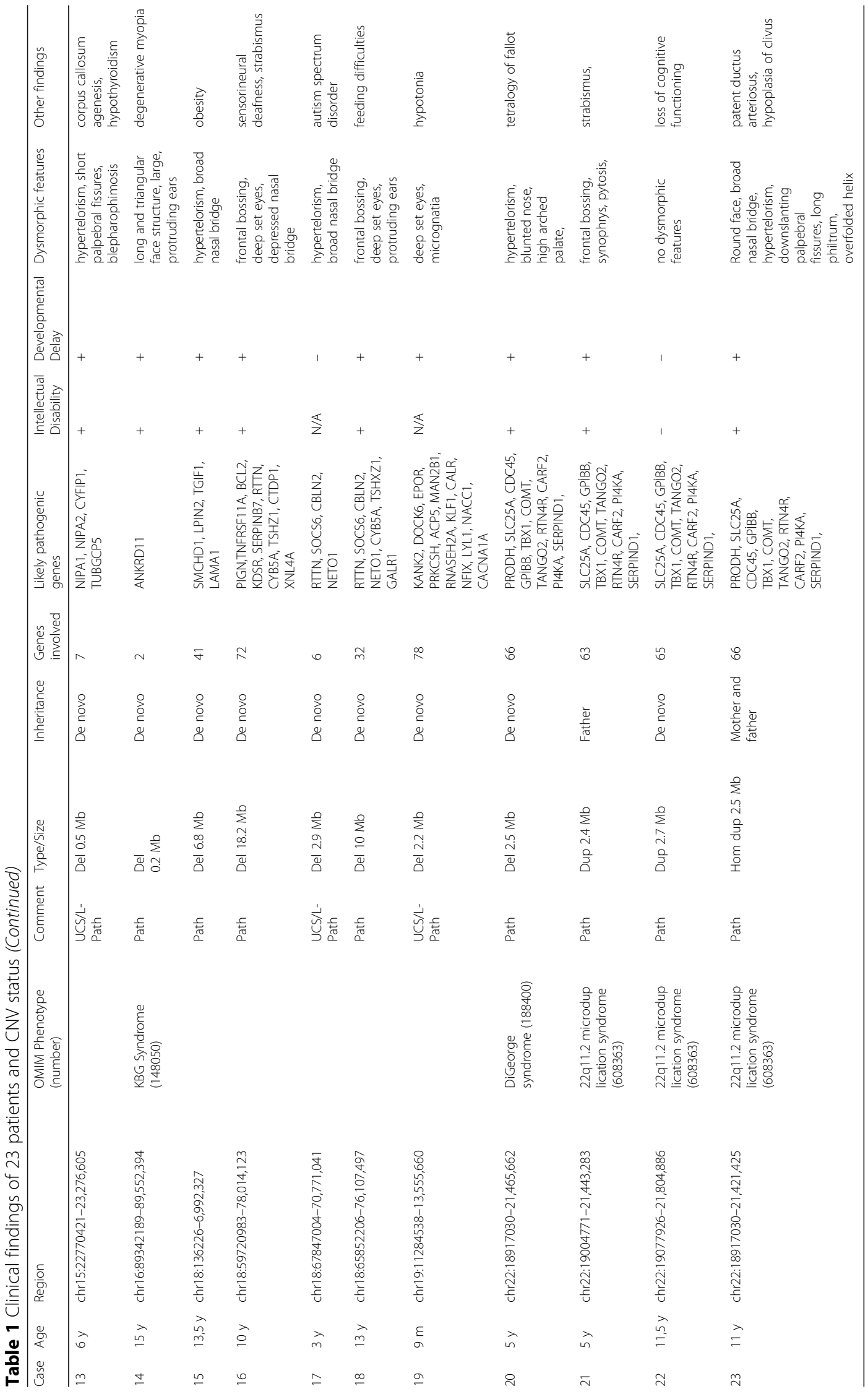




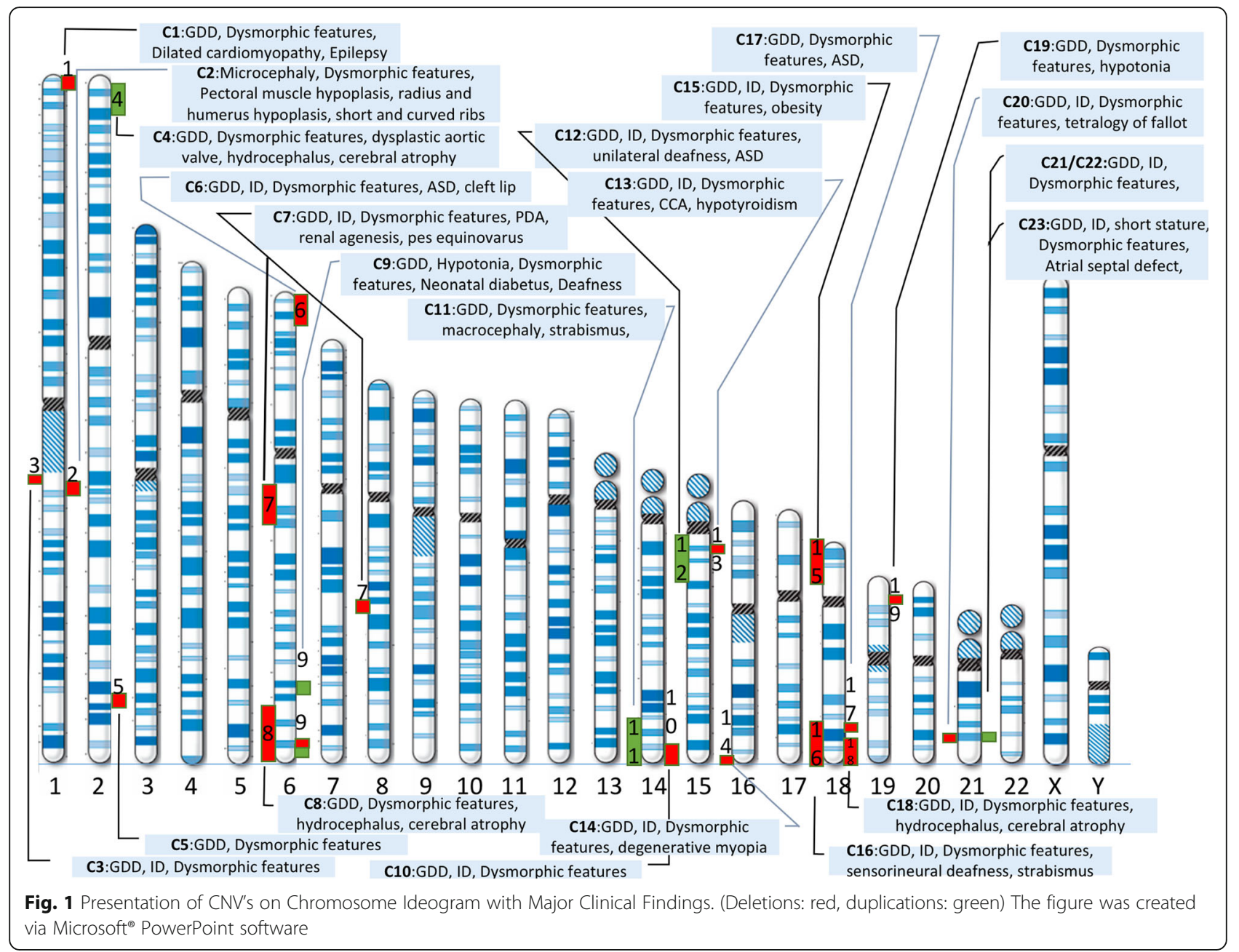

Region 22q11.2 duplication/ homozygote duplication family (cases 23 in Table 1)

An 11-year-old male patient (case 23) was diagnosed with learning disabilities. He started to walk in his first year and began speaking two-word sentences at the age of two. He was unable to learn how to read and write in his native language in the first year of elementary school, and was not able to keep up with his classmates. His history revealed that he had been hospitalized during the neonatal period due to high indirect bilirubinemia. His parents have a consanguineous marriage (Fig. 2a).

At his neurological examination, head circumference was $52 \mathrm{~cm}$ (25th-50th percentile), height was $121 \mathrm{~cm}$ ( $<3$ rd percentile), and weight was $25 \mathrm{~kg}$ ( $<3$ rd percentile). Round face, a broad nasal bridge, hypertelorism, downslanting palpebral fissures, long philtrum, and over-folded helix were observed (Fig. 2b). Hyperactivity and attention deficit disorder were not detected. No pyramidal system involvement was present, and reflexes were normoactive. Cerebellar system examinations were normal except for dysmetria and dysdiadochokinesia.
Tandem gait exhibited no abnormality. Echocardiography revealed small patent ductus arteriosus. T2 weighed MRI shows basillar impression and hypoplasia of clivus. Odontoid process was measured approximately $15 \mathrm{~mm}$ above the Chamberlain line (Fig. 2e). Serum electrolytes, electroencephalography, and abdominal ultrasonography were normal. Psychometric evaluation revealed borderline mental disability. $2.5 \mathrm{Mb}$ triplication or homozygote duplication was detected at 22q11.2/ Di George Syndrome region with CMA. Both his mother and father had the duplication of same region. The results were in accordance with the MLPA analysis (Fig. 2d).

The patient's sister is 17 years old. She started to walk in her first year and began speaking two-word sentences at the age of 18 months. She was able to learn how to read and write in her native language in the first year of elementary school but she failed in mathematics. It was reported that she spoke less than her classmates and struggled building friendships. At her neurological examination, the circumference of her head was $54 \mathrm{~cm}$ 


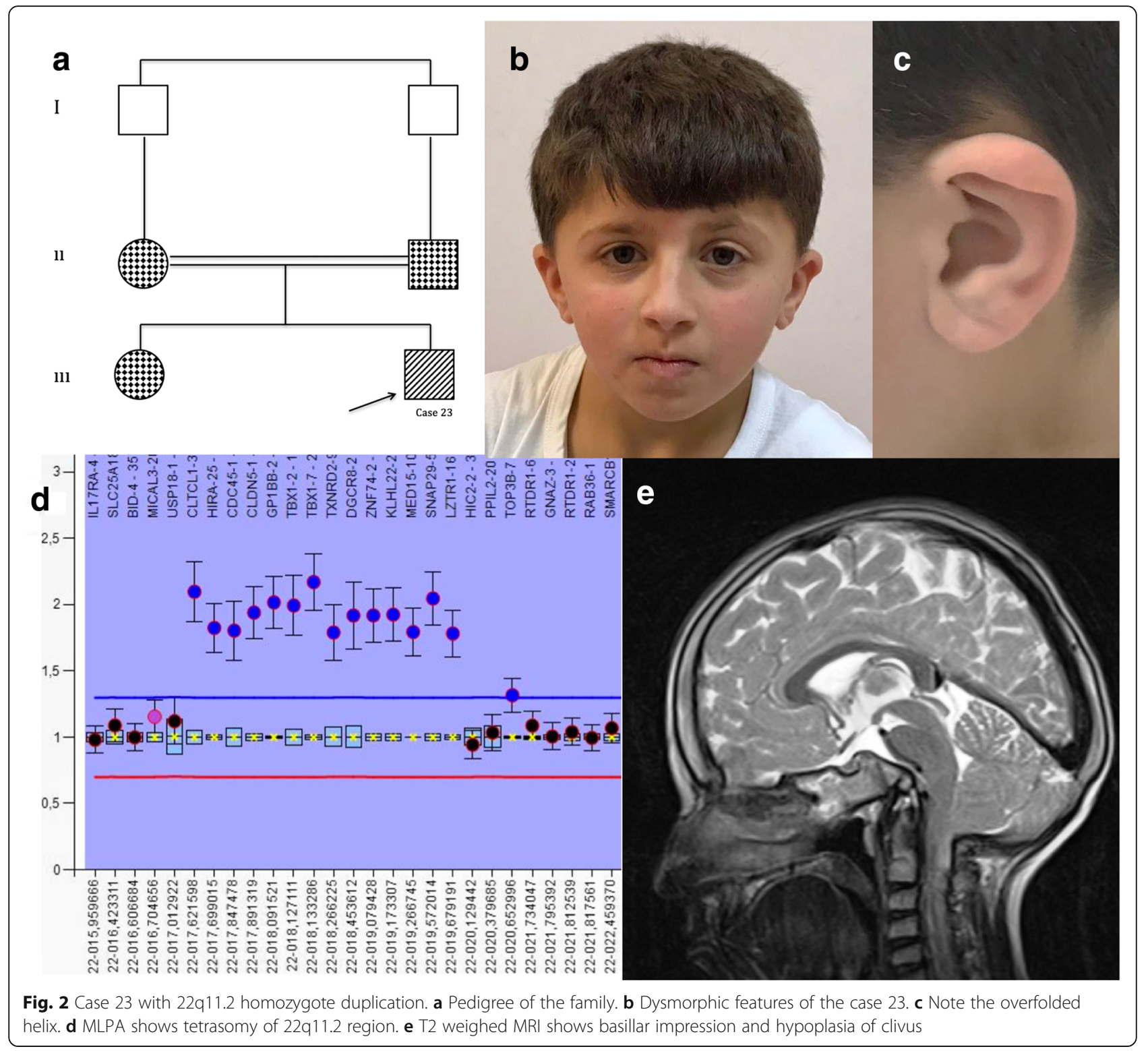

(25th-50th percentile), her height was $155 \mathrm{~cm}$ (25th50th percentile), and weight was $45 \mathrm{~kg}$ (10th-25th percentile). Hypertelorism, broad nasal bridge, downslanting palpebral fissures were observed. No pyramidal system involvement was present, and reflexes were normoactive. Echocardiography and brain MRI was normal. Psychometric evaluation revealed borderline mental disability. 2.5 Mb duplication was detected at 22q11.2/ Di George Syndrome region with CMA. The results were validated with MLPA analysis.

The patient's father is 48 years old. He is a primary school graduate and works in the transportation sector. There were no neuropsychiatric problems observed other than sudden irritation. The mother is 44 years old.
She is a primary school graduate. She is a housewife and is interested working in her own garden. She is capable of doing daily work, but has difficulty doing arithmetic calculations. Both the mother and the father had the duplication of the same 22q11.2/ Di George Syndrome region with CMA. The results were validated with MLPA analysis.

\section{Case 17 with a new locus for ASD}

A 3-year-old male patient (case 17) was diagnosed with speech delay. He started to walk in his first year and began speaking by using three words at two and half years of age. At neurological examination, head circumference was $48 \mathrm{~cm}$ (10th percentile), height was $93 \mathrm{~cm}$ 
(10th-25th percentile), and weight was $13 \mathrm{~kg}$ (10th25th percentile). Hypertelorism, broad nasal bridge, micrognatia were observed. Hyperactivity and poor eye contact were detected. No pyramidal system involvement was present, and reflexes were normoactive. Cerebellar system examinations were normal. Serum electrolytes, electroencephalography, and abdominal ultrasonography findings were within normal limits. He had stereotypical behaviors, deficits in communication, and autism spectrum disorder, which was diagnosed at 3 years of age. Denver developmental screening test showed one-year delay in speech and social skills. CMA revealed 2.9-Mb de novo deletion at $18 \mathrm{q} 22$ region. RTTN, SOCS6, CBLN2, NETO1 genes were located at the deleted region.

\section{Discussion}

Global developmental delay is the term that is used to describe children (aged 5 years or younger) who have demonstrated several significant delays in the following areas: cognitive, speech, social/personal, fine/gross motor, and daily activities. Intellectual disability is a disorder with intellectual and adaptive deficits and can be diagnosed after the age of five [5]. CMA is a first-tier test in the evaluation of individuals with ID and GDD which provides opportunities to discover new ID/GDD associated syndromes, and helps uncover the genetic background of many syndromes by revealing genetic heterogeneity and by identifying new loci for novel candidate genes [3]. The widespread use of CMA allows patients to be diagnosed and provides families with guidance in genetic counseling.

This is the first study shows the diagnostic rate of chromosomal abnormalities in the northern part of Turkey, with yield of $18.55 \%$, which is consistent with the results of previous studies (5-35\%) [2, 3]. It is important to point out that our diagnostic rate is higher than the rate of other studies performed on a similar platform in Turkey $(12-13.6 \%)[8,9]$. We found 26 CNV's in 23 patients, which indicates the importance of the CMA. Different diagnostic rates for different publications are related to the choice of patient group. If more patients were involved in the study, the rates could differ.

We also included parents in our study, and 23 of 26 CNVs were de novo. Although 8 out of 23 families had consanguineous marriages, our analyses revealed de novo variations in these families rather than homozygous mutations. In Turkish society, where the consanguineous marriage is common, it is necessary to investigate chromosomal abnormalities due to this phenomenon. We studied such a family, where mother and father were related and had a chromosome 22q11.2 duplication. The family had a girl with learning disability and was diagnosed with 22q11.2 duplication, and a boy (case 23) with milder intellectual disability, dysmorphic features and short stature, who was diagnosed with tetrasomy of 22q11.2 region. In case 23, parents' diagnoses support the duplication of region 22q11.2 in both alleles, which can be described as homozygous duplication. Case 23 is the fifth patient diagnosed with 22q11.2 tetrasomy in the literature $[4,10,11]$ and the third patient diagnosed with 22q11.2 homozygote duplication (Table 2). In other published 22q11.2 tetrasomy cases, three copies of an allele were reported. Bi et al. reported two cases with 22q11.2 homozygote duplication. However, there are other genomic changes, outside the 22q11.2 region, which could affect the phenotype of these patients [11]. As those two patients have region 22q11.2 homozygote duplication, case 23 can be added to this list as the third patient with a similar situation. Although our patient has cognitive deficiency and dysmorphic facial features in common with the other three cases, it is important to note that our patient does not suffer from hearing loss unlike the other three cases (Table 2). However, while other triplications may be three copies of a parental tract, it should be noted that our patient's mother and father have duplication of the region. Bi et al. reported that there was no phenotypic difference between duplication of 22q11.2 region and triplication of 22q11.2 [11]. While the T2 weighed MRI of the case 23 shows basillar impression and hypoplasia of clivus, hypoplasia of clivus has not been reported in the other region 22q11.2 triplication or duplication cases.

Case 17, who was diagnosed with autism spectrum disorder, had a $2.9 \mathrm{Mb}$ deletion at $18 \mathrm{q} 22$ region. RTTN, SOCS6, CBLN2, NETO1 genes are located at this region. RTTN homozygote mutations are associated with microcephaly, short stature, and polymicrogyria with seizures (OMIM 614833). [12]. Homozygote mutations of this gene also affect brain migration and volume [12]. Our patient had a deletion of 1-10th exons with milder phenotype. The MRI was normal and he had speech delay and autism spectrum disorder. These results show that the RTTN gene heterozygous mutations could be responsible for ASD.

SOCS6 gene, which encodes Suppressor of Cytokine Signaling 6 protein, was deleted in case 17. The SOCS6 gene has not yet been associated with a disease, however it may be related to syndromic obesity [13]. Although this gene is deleted in our patient, he is not yet obese. Even though SOCS6 and SOCS7 have been reported to be necessary for cortical neuron migration [14], there was no evidence of migration defect in the MRI of our patient. The other gene in the deletion region in case 17, which may be important for ASD/ID, is CBLN2. CBLN2 gene encodes Precerebellin 2. Common variants of $C B L N 2$ are associated with increased risk of pulmonary arterial hypertension [15]. It is noteworthy that CBLN2 expression is highest in cerebral cortex and hypothalamus of mouse reference [16]. 
Table 2 Clinical features of patients with tetrasomy of region 22q11.2

\begin{tabular}{|c|c|c|c|c|}
\hline Features & Yobb et al. 2005 & Bi et al. 2012 & Vaz et al. 2015 & This study (case 23) \\
\hline $22 q 11.2$ region & 4 copies $(3 / 1)$ & 4 copies $(2 / 2)$ & 4 copies $(3 / 1)$ & 4 copies $(2 / 2)$ \\
\hline Age at last evaluation & 8 years & 29 mounts & 20 years & 11 years \\
\hline Gender & Female & Male & Female & Male \\
\hline Heart defect & - & - & + & + \\
\hline Velopharyngeal insufficiency & - & - & + & - \\
\hline Hearing impairment & + & + & + & - \\
\hline Failure to thrive & - & - & - & + \\
\hline Sleep apnea & - & N/D & + & - \\
\hline Urogenital abnormalities & - & N/D & + & - \\
\hline Cognitive deficits & + & + & + & + \\
\hline Psychiatric disorders & - & N/D & + & - \\
\hline Behavioural problems & + & N/A & - & - \\
\hline Headache & - & N/D & + & - \\
\hline Recurrent infections & + & - & - & - \\
\hline Hand/foot abnormality & + & + & - & - \\
\hline Dysmorphic and other features & $\begin{array}{l}\text { Epicanthal folds, } \\
\text { Broad nasal bridge, } \\
\text { Left ear pit, Secondary } \\
\text { hearing impairment }\end{array}$ & $\begin{array}{l}\text { Left preauricular } \\
\text { pit, Plagiocephaly, } \\
\text { Facial asymmetry, } \\
\text { Teeth abnormality, } \\
\text { Hypoplastic iris and } \\
\text { corectopia }\end{array}$ & $\begin{array}{l}\text { Long narrow face, } \\
\text { Epicanthal folds, } \\
\text { Hypertelorism, } \\
\text { Downslanting } \\
\text { palpebral fissures, } \\
\text { Prominent nose, } \\
\text { Long philtrum, } \\
\text { Dental cavities, } \\
\text { Retrognathia, }\end{array}$ & $\begin{array}{l}\text { Round face, } \\
\text { Hypertelorism, } \\
\text { Downslanting } \\
\text { palpebral fissures } \\
\text { Broad nasal bridge, } \\
\text { Long philtrum, } \\
\text { Overfolded helix, } \\
\text { Hypoplasia of clivus }\end{array}$ \\
\hline
\end{tabular}

Neuropilin and Tolloid-Like 1 (NETO1) gene was deleted in case 17. NETO1 is a CUB domain-containing transmembrane protein, which have been reported to immuno-precipitate with assembled NMDA receptors via GluN2A or GluN2B subunits [17]. Ng D et al. have shown that NETO1 plays a critical role in maintaining the delivery or stability of NR2A-containing NMDARs at CA1 synapses [18].

Cody et al. reported that genes located distal to $18 \mathrm{q}$ were associated with ASD, and NETO1 was among these genes [19]. The only common point between the deletion in our patient and the region that Cody et al. have reported is the NETO1. O'Donnell et al. also reported that NETO1 and FBXO15 genes in region 18q22.3 may be risk factors for ASD [20]. When the synaptic plasticity is thought to be important in the development of ASD, heterozygous NETO1 deletions may be considered as a risk factor for ASD. After doing a thorough evaluation of the literature, particularly the studies with mice, we conclude that NETO1 should be added to the list of risky genes that should be investigated for ASD.

\section{Conclusion}

Our data expand the spectrum of $22 \mathrm{q} 11.2$ region mutations and provide insights for genotype-phenotype correlations of ID, GDD, and autism. It also underlines the importance of CMA and its use in understanding the pathophysiology of certain diseases. Based on our findings, we suggest that CMA should be used as a first-step test for the identification of new loci and the expansion of known phenotypes.

\section{Abbreviations}

ASD: Autism spectrum disorder; CA: Congenital anomalies;

CMA: Chromosomal microarray analysis; CNVs: Copy number variations; DQ: Dosage quotient; GDD: Global developmental; ID: Intellectual disability; MLPA: Multiplex ligation-dependent probe amplification; UCS: Uncertain clinical significance;

\section{Acknowledgements}

We would like to thank the family of our patient for their assistance with the clinical evaluation.

\section{Databases}

Database of Chromosomal Imbalance and Phenotype in Humans Using Ensemble Resources [http://decipher.sanger.ac.uk].

Database of Genomic Variants [http://projects.tcag.ca/variation] Online Mendelian Inheritance in Man [http://omim.org].

ClinGen Clinical Genome Resource [https://www.clinicalgenome.org]. University of California, Santa Cruz [https://genome.ucsc.edu].

Funding

This study was not supported by any foundation.

\section{Availability of data and materials}

All data generated or analysed during this study are included in this published article. Detailed clinical information of the patients reported in this 
paper are however available from the corresponding author on reasonable request.

\section{Authors' contributions}

ACC designed the study. ACC and SC performed the experiments, analyzed the data and wrote the manuscript. ACC, SC, HBE, IS and, EAA are the main referring clinicians and performed the clinical assessment and physical examination of patients. ME performed the MLPA of the 22q11.2 chromosome region. All authors read and approved the final manuscript.

\section{Ethics approval and consent to participate}

This work was approved by the Health Ethics Committee of Karadeniz Technical University, School of Medicine. Written informed consent for patients' inclusion in the study was obtained from their parents. All procedures were performed in accordance with the Declaration of Helsinki.

\section{Consent for publication}

Informed written consent was obtained from parents for publication for images and other clinical information relating to this case to be reported for academic purpose.

\section{Competing interests}

The authors declare that they have no competing interests.

\section{Publisher's Note}

Springer Nature remains neutral with regard to jurisdictional claims in published maps and institutional affiliations.

\section{Author details}

${ }^{1}$ Trabzon Kanuni Training and Research Hospital, Medical Genetics Unit, Trabzon, Turkey. ${ }^{2}$ Ankara Yıldırım Beyazı University, Ankara Atatürk Training and Research Hospital, Department of Medical Genetics, Ankara, Turkey. ${ }^{3}$ Ankara Diskapi Yildirim Beyazit Training and Research Hospital, Medical Genetics Unit, Ankara, Turkey. ${ }^{4}$ Karadeniz Technical University, School of Medicine, Department of Child Neurology, Trabzon, Turkey. ${ }^{5}$ Kayseri Training and Research Hospital, Department of Medical Genetics, Kayseri, Turkey.

Received: 14 May 2018 Accepted: 17 September 2018

Published online: 24 September 2018

\section{References}

1. Curry CJ, Stevenson RE, Aughton D, Byrne J, Carey JC, Cassidy S, et al. Evaluation of mental retardation: recommendations of a consensus conference. American College of Medical Genetics Am J Med Genet. 1997 72:468-77.

2. Sagoo GS, Butterworth AS, Sanderson S, Shaw-Smith C, Higgins JP, Burton $\mathrm{H}$. Array $\mathrm{CGH}$ in patients with learning disability (mental retardation) and congenital anomalies: updated systematic review and meta-analysis of 19 studies and 13,926 subjects. Genet Med. 2009;11:139-46.

3. Miller DT, Adam MP, Aradhya S, Biesecker LG, Brothman AR, Carter NP, et al. Consensus statement: chromosomal microarray is a first-tier clinical diagnostic test for individuals with developmental disabilities or congenital anomalies. Am J Hum Genet. 2010;86:749-64.

4. Yobb TM, Somerville MJ, Willatt L, Firth HV, Harrison K, MacKenzie J, et al. Microduplication and triplication of 22q11.2: a highly variable syndrome. Am J Hum Genet. 2005;76:865-76.

5. DSM-V. The 5th. Edition of the diagnostic and statistical manual of mental disorders from the American Psychiatric Association. In: American Psychiatric Association; 2013.

6. Wright CF, Fitzgerald TW, Jones WD, Clayton S, McRae JF, van Kogelenberg $M$, et al. Genetic diagnosis of developmental disorders in the DDD study: a scalable analysis of genome-wide research data. Lancet. 2015;385:1305-14.

7. Kearney HM, Thorland EC, Brown KK, Quintero-Rivera F, South ST, Working Group of the American College of medical genetics laboratory quality assurance C. American College of Medical Genetics standards and guidelines for interpretation and reporting of postnatal constitutional copy number variants. Genet Med. 2011:13:680-5.

8. Utine GE, Haliloglu G, Volkan-Salanci B, Cetinkaya A, Kiper PO, Alanay Y, et al. Etiological yield of SNP microarrays in idiopathic intellectual disability. Eur J Paediatr Neurol. 2014;18:327-37.
9. Ozyilmaz B, Kirbiyik O, Koc A, Ozdemir TR, Kaya OO, Guvenc MS, et al. Experiences in microarray-based evaluation of developmental disabilities and congenital anomalies. Clin Genet. 2017;92:372-9.

10. Vaz SO, Pires R, Pires LM, Carreira IM, Anjos R, Maciel P, et al. A unique phenotype in a patient with a rare triplication of the $22 q 11.2$ region and new clinical insights of the 22q11.2 microduplication syndrome: a report of two cases. BMC Pediatr. 2015;15:95.

11. Bi W, Probst FJ, Wiszniewska J, Plunkett K, Roney EK, Carter BS, et al. Cooccurrence of recurrent duplications of the DiGeorge syndrome region on both chromosome 22 homologues due to inherited and de novo events. J Med Genet. 2012;49:681-8.

12. Kheradmand Kia S, Verbeek E, Engelen E, Schot R, Poot RA, de Coo IF, et al. RTTN mutations link primary cilia function to organization of the human cerebral cortex. Am J Hum Genet. 2012;91:533-40.

13. Vuillaume ML, Naudion S, Banneau G, Diene G, Cartault A, Cailley D, et al. New candidate loci identified by array-CGH in a cohort of 100 children presenting with syndromic obesity. Am J Med Genet A. 2014;164A:1965-75.

14. Lawrenson ID, Krebs DL, Linossi EM, Zhang JG, McLennan TJ, Collin C, et al. Cortical layer inversion and deregulation of Reelin signaling in the absence of SOCS6 and SOCS7. Cereb Cortex. 2017;27:576-88.

15. Ma L, Chung WK. The genetic basis of pulmonary arterial hypertension. Hum Genet. 2014:133:471-9.

16. Wei P, Pattarini R, Rong Y, Guo H, Bansal PK, Kusnoor SV, et al. The Cbln family of proteins interact with multiple signaling pathways. J Neurochem. 2012;121:717-29.

17. Cousins SL, Innocent N, Stephenson FA. Neto1 associates with the NMDA receptor/amyloid precursor protein complex. J Neurochem. 2013;126:554-64.

18. Ng D, Pitcher GM, Szilard RK, Sertie A, Kanisek M, Clapcote SJ, et al. Neto1 is a novel CUB-domain NMDA receptor-interacting protein required for synaptic plasticity and learning. PLoS Biol. 2009;e41:7.

19. Cody JD, Hasi M, Soileau B, Heard P, Carter E, Sebold C, et al. Establishing a reference group for distal 18q-: clinical description and molecular basis. Hum Genet. 2014;133:199-209.

20. O'Donnell L, Soileau B, Heard P, Carter E, Sebold C, Gelfond J, et al. Genetic determinants of autism in individuals with deletions of 18q. Hum Genet. 2010;128:155-64.
Ready to submit your research? Choose BMC and benefit from:

- fast, convenient online submission

- thorough peer review by experienced researchers in your field

- rapid publication on acceptance

- support for research data, including large and complex data types

- gold Open Access which fosters wider collaboration and increased citations

- maximum visibility for your research: over $100 \mathrm{M}$ website views per year

At BMC, research is always in progress.

Learn more biomedcentral.com/submissions 